\title{
AS RELAÇÕES NEURAIS DE INTERAÇÃO E INTEGRAÇÃO ENTRE RACIOCÍNIO MORAL E EMOÇÕES: UM DIÁLOGO DAS NEUROCIẾNCIAS COM AS ÉTICAS CONTEMPORÂNEAS
}

\author{
THE NEURAL RELATIONS OF INTERACTION AND INTEGRATION BETWEEN MORAL \\ REASONING AND EMOTIONS: A DIALOGUE OF THE NEUROSCIENCES WITH THE \\ CONTEMPORARY ETHICS
}

\author{
LEONARDO FERREIRA ALMADA \\ (UNESP / UFU - Brasil)
}

\begin{abstract}
Resumo
Este artigo visa a analisar a significação de algumas hipóteses neurobiológicas — acerca das relações dos raciocínios morais com as emoções - que buscam uma compreensão das bases causais do comportamento humano e do percurso neural que envolve o processo de decision-making. Ao mesmo tempo, proponho defender que, se processos emocionais e processos cognitivos têm percursos neurais próprios e particulares, também é verdade que, no âmbito dos raciocínios morais e da regulação do comportamento, há uma cooperação e integração funcional significativa, a qual inviabiliza uma dicotomia ou subordinação entre processos cognitivos e processos emocionais na constituição do comportamento ético.

Palavras-chave: Neurociência afetiva, emoções e raciocínios morais, processos emocionais e cognitivos, neuroética, Epistemologia das Neurociências.
\end{abstract}

\begin{abstract}
This article aims to analyze the significance of some neurobiological hypotheses — about the relationships of moral reasoning with the emotions - which seeks an understanding of the causal basis of the human behavior, as well as of the neural pathway that involves the process of decision-making. At the same time, I propose to argue that if emotional and cognitive processes have their own neural pathways is also true that in the context of moral reasoning and regulating behavior, there is a functional cooperation and integration, which undermines a dichotomy or subordination between cognitive and emotional processes in the formation of ethical behavior.

Key-Words: Affective Neuroscience, emotions and moral reasoning, emotional and cognitive processes, Neuroethics, Epistemology of Neurosciences.
\end{abstract}

\section{Delimitação Teórico-Metodológica}

Por suas próprias características, a orientação geral que fundamenta o framework teóricometodológico deste artigo se insere em um modelo investigativo cuja estruturação tem ocorrido de modo contínuo e intenso desde o final do século XX, especialmente nos EUA e na Inglaterra: refiro-me à denominação geral e ampla de Epistemologia das Neurociências e da Psiquiatria. Deste ponto de vista mais amplo, podemos considerá-la enquanto um campo de atuação multi e interdisciplinar, que busca congregar Epistemologia, Ética, Ciências Cognitivas, Evolucionismo e Neurociências, assim visando a analisar os resultados e postulados de diversas Ciências da Mente sob um prisma ético-epistemológico. A busca por uma associação entre estes inúmeros ramos do saber 
não se justifica apenas pela colaboração recíproca que podem manter entre si. Com efeito, alguns avanços conceituais e empíricos das Neurociências dependem dessa conjunção de conhecimentos e perspectivas. Ademais, a introdução do espírito crítico-filosófico no âmbito da produção científica é o que tem gerado um crescente e profícuo interesse de cientistas por questões éticas, bem como o recurso a modelos epistemológicos que podem ser capazes de fundamentar uma análise crítica dos métodos e dos resultados experimentais que são obtidos com aparelhos de neuroimagem. Neste contexto, a orientação que assumo se alicerça na possibilidade de estarmos atento aos resultados científicos, de modo a podermos acrescentar novos dados a certos problemas de Ética, sem que, para tanto, sejamos movido por uma crença dogmática e irrestrita na metodologia e nos resultados obtidos pelas diversas Ciências da Mente.

Por outro lado, o caráter amplo e vago que caracteriza a expressão Epistemologia das Neurociências e da Psiquiatria exige de seus proponentes o esforço de definir especificações mais precisas, buscando dissociar uma série de modelos e interesses investigativos que podem ser açambarcados por esse campo de atuação geral. Neste sentido, é necessário e pertinente ressaltar que meu interesse mais específico se direciona para os modelos investigativos que, no âmbito da Neurociência da Ética, visam a fomentar o debate acerca de importantes e clássicos problemas do comportamento humano (especialmente os processos de decision-making) a partir da interface entre a produção filosófica e a produção científica

O modelo investigativo que fundamenta a orientação teórica deste artigo postula que o recente contato de neurocientistas com um background filosófico não pode justificar um interesse explícito de assumir posição conflitante em relação a modelos éticos tradicionais e tampouco a certas correntes das Éticas contemporâneas. No entanto, é também verdade que as últimas décadas têm constituído uma situação ambígua e delicada no diálogo entre Filosofia e Ciências da Mente: ao lado do interesse filosófico despertado por certas investigações e hipóteses neurocientíficas, os meios acadêmicos também têm sido invadidos por um acentuado e natural mal-estar, gerado pela orientação fisicalista e reducionista que muitas vezes tem caracterizado as Neurociências. Sem dúvida, um fisicalismo reducionista sem ponderações exclui qualquer hipótese de diálogo entre Filosofia e Ciência. Refiro-me, em outras palavras, a um extremismo das constantes e reiteradas tentativas, por parte de neurocientistas, de fundamentar modelos éticos cuja particularidade consiste na tentativa de reduzir inúmeros aspectos do comportamento a específicas atividades neuroquímicas, neurofuncionais e neuroelétricas que inerem à atividade cerebral. Por vezes, o que parece mais grave, alguns modelos reducionistas sequer levam em consideração os mecanismos ambientais que, sem dúvida, modulam diferenças e individualidades.

Em princípio, o contato das Neurociências com problemas eminentemente éticos objetiva justificar os aspectos empíricos que estão na base dos inúmeros comportamentos que nos aproximam e/ou distinguem dos outros primatas. Esta característica, que apresenta suas limitações, tem, por 
outro lado, a vantagem de trazer novas configurações e novos dados para certos problemas éticos que surgiram e vêm surgindo no âmbito dos valores socialmente aceitos e rejeitados, mediante a pesquisa científica do cérebro e as implicações geradas pelo exitoso e ao mesmo tempo controverso uso das novas tecnologias de neuroimagem, como o EEG (Eletroencefalograma), a MRI (magnetic resonance imaging), a fMRI (Functional magnetic resonance imaging), o PET (positron emission tomography), o SPECT (single photon emission computed tomography) e as técnicas imunocitoquímicas, cuja função é averiguar as linguagens químicas dos circuitos neuronais. Decerto, essas novas tecnologias e os correspondentes estudos, teorias e modelos científicos são capazes de criar circunstâncias no interior das quais as questões éticas podem se defrontar com novos e reiterados desafios.

\section{Delimitação do Problema}

Há mais de dois milênios, o debate sobre a natureza moral do homem ocupa posição privilegiada nas discussões envolvendo filósofos, teólogos, juristas e moralistas. Apenas recentemente, porém, foi possível iniciar a busca por um conhecimento empírico da organização neural que corresponde ao comportamento moral. Segundo os neurocientistas Jorge Moll, Ricardo de Oliveira-Souza e Paul Eslinger (2003, p. 299), esse avanço qualitativo para um conhecimento estruturado em bases empíricas muito se deve à análise de pacientes com "drásticas mudanças no comportamento social" em função de "lesões cerebrais adquiridas", assim como ao "estudo do comportamento normal e patológico com aparelhos de neuroimagem funcional e estrutural". Daí porque acreditam que o uso dos aparelhos de neuroimagem funcional e estrutural tem mostrado que grande parte do "comportamento humano é implicitamente moral e resulta de múltiplos processos psicológicos e neurobiológicos que teoricamente se situam sobre um continuum entre os extremos da pró-sociabilidade e da anti-sociabilidade” (Moll, Oliveira-Souza e Eslinger, 2003, p. 299).

Com efeito, as chamadas "ações moralmente dirigidas" têm sido tradicionalmente atribuídas a processos lógicos e verbais que costumamos designar por "raciocínios morais e julgamentos". Entretanto, e em princípio, o dado mais importante do problema é o fato de que as declarações lógico-verbais conscientes muitas vezes são falhas e limitadas em sua tentativa de prever condutas morais na vida cotidiana. Ao mesmo tempo, o reconhecimento de que as emoções morais exercem um poderoso efeito sobre o comportamento humano tem estimulado e incentivado a realização de inúmeros testes, assim como a formulação de inúmeras hipóteses sobre o comportamento de alguns indivíduos que desenvolveram ou adquiriram um comportamento antissocial como resultado de específicos danos cerebrais. De fato, se tais pesquisas estão ainda em fase inicial, também é verdade que os resultados já existentes desde o final do século XX parecem sugerir engenhosas e instigantes hipóteses para antigos paradoxos morais, como o "falar bem e agir mal", assim como têm lançado 
luz sobre os atributos neurobiológicos exclusivamente humanos no comportamento ético.

\section{Raciocínios morais e emoções: relações de interação e integração}

A cognição e a sensitividade social constituem claras consequências da evolução biológica e cultural da humanidade. A capacidade de desenvolver a cognição e a sensitividade social — já desenvolvida por nossos ancestrais hominídeos e primatas — inclui, basicamente, "a capacidade de assimilação de regras baseadas sobre recompensas/punições e a atribuição de intenções, crenças, sensações e desejos a outras pessoas" (Moll, Oliveira-Souza e Eslinger, 2003, p. 299). Os primatas superiores, como os homens, são dotados de um grande repertório de comportamentos sociais, dentre os quais o senso de justiça, que, de certa maneira, permeia seus comportamentos intrapessoais. Ao que parece, são essas habilidades que constituem os elementos mais incisivos no que diz respeito à origem da moralidade humana. Inúmeras emoções morais podem ser designadas, nesse sentido, como emoções sociais ou sócio-morais. No entanto, se as emoções básicas geram ideias, imaginações, lembranças ou percepções dotadas de relevância pessoal imediata, são as emoções morais que "se relacionam com o interesse e o bem-estar tanto da sociedade como um todo quanto pelo menos de duas pessoas além do juiz e do agente" (Moll, Oliveira-Souza e Eslinger, 2003, p. 299). Nesse mesmo sentido, as emoções morais são naturalmente evocadas e trazidas à luz em função de circunstâncias que extrapolam sua própria esfera imediata. As emoções morais constituem os principais elementos integrantes na coesão e ordem de um grupo social, razão pela qual parecem estar presentes no homem primitivo de forma importante para os processos de caça, partilha de alimentos e coleta. É também sob a influência das mesmas emoções morais que podemos compreender os comportamentos pró-sociais, como culpa, gratidão e compaixão, assim como os comportamentos que promovem a dissolução de um grupo e sua reorganização social.

Do ponto de vista do cálculo moral, há situações em que as emoções evocadas são falhas ou insuficientes para lidar com certas demandas contextuais. Essas demandas são basicamente inerentes às situações que envolvem dilemas morais. Um dilema moral é uma situação problemática, no interior da qual existem emoções morais dissonantes com forças comparáveis, o que engendra lentos e poderosos processos, conhecidos como raciocínios morais. Nestes casos, as decisões ou juízos morais se tornam muito dependente da análise e da lógica verbal dos modos de pensar. Com efeito, esses processos, conhecidos como raciocínios morais, mostram ainda os mesmos neurocientistas, pressupõem que as expressões dos "conflitos internos entre as emoções morais possam ser suprimidas para que as ações sejam guiadas pela interação de resultados previstos de escolhas individuais no âmbito de um incerto terreno de possibilidades" (Moll, Oliveira-Souza e Eslinger, 2003, p. 300). Mas o fato é que as habilidades cognitivas de ordem superior acabam se 
tornando elementos decisivos no contexto das decision-making; por outro lado, o "planejamento, a flexibilidade executiva e a aplicação de estratégias devem trabalhar a serviços de ações cuja motivação original é moral e emocional" (Moll, Oliveira-Souza e Eslinger, 2003, p. 300).

A instituição dos postulados de que (i) grande parte do comportamento humano supõe a influência das emoções no raciocínio moral e de que (ii) a formação do pensamento moral resulta de específicos e múltiplos processos psicológicos e neurobiológicos é suficiente para demonstrar em que sentido as Neurociências se propõem consolidar a promessa que vem realizando desde meados do século XX: depreender, da relação dos raciocínios morais com as emoções, um caminho privilegiado para a compreensão objetiva e em bases causais do comportamento humano e do percurso neural que envolve os processos de decision-making. Um estudo polêmico e relativamente recente $^{1}$ indica que os estados emocionais influenciam seletivamente a atividade neural que se relaciona com a cognição no córtex pré-frontal (CPF) lateral, assim indicando uma forte integração e interação emoção-cognição, fato particularmente rejeitado por parte da tradição filosófica ocidental, e relativizado por inúmeros neurocientistas. Tais estudos, porém, geram grande interesse para o estudo filosófico e científico do comportamento ético, principalmente pelas relações que estabelecem entre raciocínios morais e emoções. Consoante os proponentes da pesquisa, emoção e cognição contribuem, de maneira conjunta e igual, para o controle do pensamento e do comportamento: todo comportamento e todo pensamento moral supõe relações intrínsecas entre processos emocionais e processos cognitivos. Indo de encontro a uma série de pesquisas, teorias e modelos que não consideram a integração entre aspectos cognitivos e emocionais, estes pesquisadores recorreram a fMRI para examinar e manipular a conjunção das tarefas cognitivas e dos estados mentais na atividade cerebral, focando especificamente no córtex pré-frontal lateral, "um local em potencial para a integração emoção-cognição". Após o cumprimento das etapas necessárias à pesquisa, os neurocientistas chegaram à seguinte conclusão: "não apenas a emoção contribui para a relação do pensamento e comportamento, mas também a cognição pode contribuir para a regulação da emoção" (Gray, Braver e Raichle, 2002, p. 4115-4116).

Tal conclusão, em toda sua amplitude, não é unânime entre os neurocientistas. Com efeito, uma das mais importantes e divulgadas obras na área de Neurociência, The emotional brain, de Joseph LeDoux, assume, em princípio, propósitos distintos. Contra os rumos da Neurociência Cognitiva, e visando a enfatizar as funções cerebrais responsáveis pelas emoções em relação às funções cerebrais responsáveis pelos processos cognitivos, LeDoux (1996, p. 69-70) estabelece, de maneira bem precisa, que os processos emocionais possuem clara independência em relação aos processos cognitivos, tanto por suas origens quanto por suas funções. Eis como sua posição é apresentada:

(i) Quando certa região do cérebro é danificada, animais e homens perdem a capacidade de apreciar a significação emocional de certos estímulos sem nenhuma perda da capacidade de perceber esses estímulos como objetos; 
(ii) O significado emocional dos estímulos pode começar a ser apreciado pelo cérebro antes do sistema perceptual ter processado totalmente o estímulo. É realmente possível ao cérebro saber se alguma coisa é boa ou má antes de saber exatamente o que é;

(iii) Os mecanismos do cérebro através dos quais as memórias da significação emocional dos estímulos são registradas, armazenadas e recuperadas são diferentes dos mecanismos através dos quais as memórias cognitivas dos mesmos estímulos são processadas;

(iv) Os sistemas que realizam apreciações emocionais são diretamente conectados com os sistemas envolvidos no controle das respostas emocionais. Uma vez a apreciação sendo realizada por esses sistemas, as respostas ocorrem automaticamente. Em contrapartida, sistemas envolvidos em processos cognitivos não são hermeticamente acoplados com o sistema de controle de resposta. $\mathrm{O}$ apanágio dos processos cognitivos é a flexibilidade das respostas na base dos processos. A cognição nos fornece escolhas. Em contraste, a ativação dos mecanismos de apreciação estreita as opções de resposta para as poucas escolhas que a evolução sabiamente nos forneceu para conexão com um específico mecanismo de apreciação. A ligação entre processos de apreciação e mecanismos de resposta constituem mecanismos fundamentais de emoções específicas. E, por fim;

(v) A ligação dos mecanismos de apreciação com os sistemas de controle de resposta significa que os mecanismos de apreciação detectam um evento significativo, sua programação e até mesmo a execução de um ajuste de repostas apropriadas que ocorrerão. As sensações corporais usualmente acompanham apreciações e, quando acontecem, são apenas uma parte da experiência consciente das emoções. Porque os processos cognitivos não se relacionam com respostas em caminhos obrigatórios, intensas sensações corporais têm menos probabilidade de ocorrer em associação com esses pensamentos.

Em verdade, mais do que cindir processos cognitivos de processos emocionais, LeDoux pretende instituir a anterioridade dos processos emocionais na estruturação do comportamento moral. Sem embargo, os experimentos de LeDoux não excluem a ideia de que a emoção se relaciona em nível funcional com a cognição. Mais precisamente, ele afirma, de modo categórico, que processos emocionais e processos cognitivos interagem nos níveis funcional, neurofisiológico e neuroanatômico. Se processos emocionais e processos cognitivos têm percursos neurais próprios e particulares, também é verdade que, no âmbito dos raciocínios morais e da regulação do comportamento, há uma cooperação e integração funcional. Eis o que é preciso destacar: ainda que a cognição possa exercer papel relevante na regulação da emoção, é preciso cautela quando se atribui à racionalidade um papel anterior ou primaz em relação às emoções. Mais que isso, as emoções estão no núcleo das relações entre pensamento e comportamento, regulando de maneira significativa nossos raciocínios morais. Esses apontamentos são particularmente relevantes para a discussão Ética e filosófica, pois pode lançar novos dados e estabelecer novas bases para o diálogo entre razão e emoção. Como sabemos, as relações entre razão e emoção constituem um problema 
filosófico bem definido desde os gregos, ainda que, sob a influência da cultura greco-romana e da cultura judaico-cristã, o modo como o ocidente compreendeu a natureza dos afetos muito prejudicou a hipótese de um conhecimento mais sofisticado da mente humana. Com efeito, a insistência com que a racionalidade ética foi sobreposta aos afetos acabou reduzindo as emoções a dimensões que meramente refletem nossa incompletude e imperfeição.

A existência de alguns preconceitos teóricos que sustentaram a primazia teórica da razão é certamente o que justifica o fato de as Neurociências terem privilegiado, ao longo de quase todo o século XX, os processos de raciocínio, pensamento e intelecto, isto é, os aspectos perceptivos e cognitivos do comportamento, atribuindo às emoções aspectos desvinculados da atividade cerebral. Ao surgirem, em meados do século XX, as Ciências Cognitivas legitimaram, uma vez mais, a exclusão do papel desempenhado pelas emoções, sustentando a honrosa posição de "a nova ciência da mente", e voltando-se apenas para o lado do cérebro que tem relação com pensamento, raciocínio e intelecto ${ }^{2}$. Estabeleceu-se, assim, a concepção, ao meu ver improcedente, de que podemos conhecer a mente sem pensar nas emoções ${ }^{3}$. E, tendo em vista muitas e recentes pesquisas em Neurociências acerca da moralidade humana, é atualmente delicado pensar o comportamento ético para além das relações de interação e integração entre raciocínios morais e emoções

O cérebro humano contém cerca de 100 bilhões de neurônios que, relacionados em amplos e complexos caminhos, dão origem a trilhões de conexões sinápticas, segundo padrões relativamente sistemáticos de interações elétricas e químicas em diferentes áreas cerebrais. De fato, as fagulhas elétricas dos intercâmbios químicos entre essas células geram fenômenos surpreendentes e inusitados; porém, é o modo como nossas emoções são formadas que se destaca como uma das mais incríveis e notáveis proezas do cérebro (LeDoux, 1996, p. 22-23). Daí porque a concepção da vida sem emoções, ou mesmo a minimização do poder dos afetos ante a conjectura de uma racionalidade superior, que supostamente governa os movimentos humanos, constitua um postulado para o qual se impõe a tarefa de revisão e reconfiguração teórico-metodológica.

\section{O pensamento da Ética entre a Filosofia e as Neurociências}

Com efeito, se, no âmbito das Neurociências, muitas são as questões que reclamam a conjunção e colaboração recíproca de diversos saberes, poucas destas, porém, despertam a mesma pluralidade de interesses que nossa (i) capacidade de gerar os mais diversos afetos, de (ii) estruturar raciocínios morais e de (iii) tomar decisões sob a influência das emoções. Refiro-me, decerto, aos

principais problemas que justificam o elo entre Neurociências, Ética e Epistemologia: a natureza da consciência e o papel das emoções e dos processos cognitivos na tomada de decisões (decisionmaking), o que inclui as questões do conhecimento, da ação e dos raciocínios e julgamentos morais.

É neste contexto que se inscreve meu interesse de sustentar e desenvolver a ideia de 
'Neurociência Afetiva' - de acordo com a vertente professada por Jaak Panksepp - enquanto um modelo ético que implica a seguinte compreensão: é preciso perscrutar, de maneira mais detida e atenta, a constituição das emoções, para que, subsequentemente, tentemos compreender a influência que podem exercer sobre os raciocínios morais e os processos de decision-making. Tal compreensão é sustentada pela premissa, advogada por qualquer orientação em 'Neurociência Afetiva', de que são os processos emocionais - incluindo os sentimentos subjetivamente experienciados - que estruturam a 'cadeia causal' de eventos que controlam as ações humanas em geral. Esta premissa está de acordo com a ideia de que distintos sistemas cerebrais geram comportamentos emocionais diferenciados, de onde resulta a possibilidade de uma taxonomia das emoções em bases neurobiológicas. E, por outro lado, a legitimação de uma natureza neurobiológica dos afetos é o que pode engendrar a crença de que são os processos emocionais que "fornecem vários tipos de valores internos naturais sob os quais muitas escolhas complexas comportamentais nos humanos são baseadas" (Panksepp, 1998, p. 14). Trata-se, neste sentido, de uma importante relação entre processos emocionais básicos e raciocínios morais mais complexos.

Em tal compreensão está subsumida a exigência de delinear os processos que envolvem a decision-making, na mesma medida em que supõem a interação e integração das emoções e da cognição em nível neural. De imediato, a maneira proposta pela Neurociência Afetiva de Jaak Panksepp para dar início a essa investigação supõe a tarefa de compreender os 'sistemas operativos' que regulam as emoções básicas no cérebro, tendo em vista a seguinte premissa: os fenômenos psicológicos e o comportamento ético dependem de muitas e distintas atividades interativas que emergem no cérebro. Trata-se da tarefa sem a qual, de acordo com o fisicalismo de Panksepp, não podemos dar conta de duas questões filosóficas e interdependentes: O que são as emoções? Como se estrutura o raciocínio moral?

Este paradigma é o que explica as razões pelas quais a Neurociência Afetiva recorre à existência de vários e específicos sistemas psicocomportamentais que inerem à atividade neural, resultando daí a exigência de identificar e demarcar os principais sistemas emocionais da estrutura cerebral humana. Daí porque tenho proposto sustentar e desenvolver a ideia de 'Neurociência Afetiva': por acreditar que um contraponto fisicalista à discussão filosófica dos raciocínios morais, da ação e dos processos de decision-making traz para a Filosofia a tarefa de assumir uma posição em relação aos resultados e postulados das pesquisas neurocientíficas, assim também gerando a possibilidade de discutir, do ponto de vista ético-epistemológico, as relações entre os comportamentos éticos e as características funcionais dos principais sistemas emocionais do cérebro.

Com a evolução dos instrumentos de neuroimagem, que permitem o estudo do cérebro em pleno funcionamento, as Neurociências se depararam com a instigante possibilidade de aferir as principais áreas cerebrais envolvidas nos processos de decision-making e, ademais, com a possibilidade de compreender as consequências e ramificações desses processos complexos. Segundo Jorge Moll e Ricardo de Oliveira-Souza (2008, p. 46), 


\begin{abstract}
A Neurociência cognitiva já pode explicar muitos dos mecanismos cerebrais que formam a base dos julgamentos morais e deliberações Éticas. Estudos empíricos examinaram questões tais como de que forma se constitui o senso de moralidade no cérebro de uma criança; de que maneira os diversos tipos de lesão cerebral afetam o julgamento moral, quais áreas do cérebro parecem estar em ação quando nos vemos diante de um impasse envolvendo questões morais que nos desnorteiam e que rumos seguem os pensamentos em meio a esses dilemas. Basta realizar uma busca na internet para "cérebro e moralidade" para se ter uma ideia do quanto essa área de estudo é fértil e crescente.
\end{abstract}

Tal é a razão pela qual o surgimento das questões Éticas na Neurociência implica a compreensão de que a Moral e a Ética deixam de ser assuntos exclusivos da Filosofia e passam a também integrar o âmbito da interface entre as Éticas e as Neurociências, surgindo daí este campo de investigação que tenho proposto. Ademais, à medida que as investigações neurocientíficas incorporam significativas informações quanto às relações que se estabelecem entre raciocínio moral e emoção - a ponto de ser atualmente possível estruturar com mais eficácia a influência dos sentimentos sobre o que julgamos moral e imoral —, os estudos científicos da Ética adquirem maior envergadura e passam a cada vez mais criar interessantes rumos para as discussões Éticas na contemporaneidade.

\title{
4.1 Dilemas pessoais morais e julgamentos impessoais morais: uma perspectiva naturalista
}

Recentes descobertas científicas alimentam e têm alimentado alguns importantes e questionados estudos científicos sobre o comportamento ético, assim como inúmeras outras polêmicas que constituem o debate contemporâneo: defende-se, enfaticamente, a existência, nos homens, de uma "rede neural moral especial"4 no interior de uma área cerebral repleta de circuitos que usam compostos bioquímicos relacionados à emoção e ao comportamento, dentre os quais a adrenalina e a serotonina. A mesma defesa se aplica à ideia de que o córtex pré-frontal é a área cerebral responsável pelo gerenciamento de algumas capacidades cognitivas que nos distinguem dos outros primatas, dentre as quais nossa sofisticada capacidade de planejamento racional e emocional. Trata-se da área cortical cujo amadurecimento tardio corresponde ao aprimoramento do raciocínio abstrato, da memória e da atenção e, especialmente, à capacidade de inibir respostas emocionais 5 . Indivíduos com lesões nesta área cortical, mais precisamente no córtex pré-frontal ventromedial (doravante CPFVM), tendem a apresentar funcionamento cerebral distinto de outros indivíduos nos momentos em que são levados a tomar decisões e a fazer opções que envolvem princípios éticos. Para tanto, neuroimagens, associadas com inúmeros testes neuropsicológicos, e no âmbito de rigorosos princípios metodológicos, tentam justificar essas relações entre raciocínios morais e emoções a partir do CPFVM como lócus privilegiado de atuação.

Michael Koenigs, Liane Young, Mark Hauser, Antonio Damásio e outros colaboradores 
(2007, p. 1) publicaram alguns resultados que parecem possuir consequências éticas significativas: lesões adquiridas no CPFVM aumentam significativamente (em situações de dilemas morais) a preferência por escolhas "pragmáticas" ou, como dizem, "utilitárias", desde que entendamos essas expressões no sentido mais vulgar e comum dos termos. Eis como apresentam a pesquisa que se tornou uma das referências para a investigação científica na área de decision-making e das relações entre raciocínios morais e emoções:

\begin{abstract}
Os processos psicológicos e neurobiológicos subjacentes aos julgamentos morais têm sido o foco de muitos estudos empíricos recentes. É de sumo interesse saber se as emoções exercem papel causal nos julgamentos morais e, em paralelo, como as áreas do cérebro relacionadas à emoção contribuem para o julgamento moral. Aqui mostraremos que pacientes com danos no córtex pré-frontal ventromedial (CPFVM), uma região do cérebro necessária para a geração normal de emoções e, em particular, para as emoções sociais, produz um anormal padrão "utilitário" de julgamentos em dilemas morais. Em contrapartida, o julgamento dos afetados foi normal em outras classes de dilemas morais. Essas descobertas indicam que, para um seletivo número de dilemas morais, os afetados são críticos para julgamentos normais de certo e errado. Essas descobertas implicam o papel necessário da emoção na geração desses julgamentos.
\end{abstract}

Os julgamentos de dilemas pessoais morais dos indivíduos com lesão no CPFVM acabam favorecendo o bem-estar agregado em detrimento do bem-estar de menor número de indivíduos, o que pode ser considerado, em princípio, uma decisão meramente "aritmética" e, portanto, "racional", também entendido no sentido mais vulgar e comum do termo, isto é, sem a conotação de mérito que atribuímos, no Ocidente, à racionalidade.

Temos aí, de imediato, uma dissociação importante entre dilemas pessoais morais e julgamentos impessoais morais. Greene e alguns colaboradores (2001, p. 2106) propuseram codificadores independentes para avaliar cada dilema moral a partir de três critérios capazes de capturar as diferenças entre o tipo intuitivamente "pessoal" (e supostamente mais emocional) de julgamento/violação exibido por um dilema proposto, e o mais intuitivamente "impessoal" (e supostamente menos emocional) tipo de julgamento/violação exibido por outro modelo de dilema. Os dilemas morais que cumprem os primeiros critérios foram designados como de condição "moral pessoal", enquanto que os outros foram designados como de condição "moral impessoal”. Dilemas morais pessoais típicos incluem uma versão do dilema passarela, um caso de roubo de órgãos de uma pessoa para distribuí-los a outras cinco pessoas, e um caso de pessoas que decidem jogar outra pessoa para fora do barco para não afundar. Dilemas morais impessoais típicos incluem uma versão do dilema do carrinho, um caso de pegar o dinheiro encontrado em uma carteira pedida, e um caso de votação de uma política que deverá causar mais mortes do que suas alternativas rivais. Neste caso, a avaliação do dilema pode ser bem compreendida com os termos de ação adequada e ação inadequada. De acordo com Greene e Haidt (2002, p. 519), e em linhas gerais, uma violação moral é pessoal nos seguintes casos: (i) a violação é suscetível de causar danos corporais graves; (ii) 
este dano pode provir e se dirigir a uma pessoa particular ou a um grupo de pessoas; (iii) o ato de gerar o dano não decorre de uma ameaça existente pelo outro. A violação moral é impessoal se não cumprir esses critérios. Esta distinção entre julgamentos/violações morais pessoais e julgamentos/ violações morais impessoais tem profundas bases evolucionárias, de acordo com Greene e seus colaboradores (2004). Há evidências que sugerem que nossos ancestrais guiavam suas vidas e ações em função de emoções, como empatia, raiva, alegria, gratidão, amor e senso de equidade, sem que, aparentemente, elaborassem qualquer raciocínio moral (entendendo raciocínio como os processos relativamente lentos e deliberativos que envolvem a abstração e pelo menos alguns componentes acessíveis pela introspecção). E, do ponto de vista evolucionário, seria realmente estranho se grande parte das ações humanas não fossem dominadas por específicas disposições sócio-emocionais. Por outro lado, também seria surpreendente se o homem, com sua profunda capacidade de abstração, não dependesse do raciocínio deliberativo e abstrato para formular julgamentos morais. Temos aí as duas faces que fundamentam os julgamentos/violações morais pessoais e impessoais. Enquanto que nossas ancestrais disposições sócio-emocionais parecem estar na base de nossa capacidade para julgamentos/violações morais pessoais, nossas capacidades mais propriamente cognitivas podem estar na base de julgamentos/violações morais impessoais.

De fato, tal dissociação remete à cisão, estabelecida por LeDoux (1996), entre processos emocionais (no caso, dilemas pessoais morais) e processos cognitivos (no caso, julgamentos impessoais morais). A supracitada lesão no CPFVM, de acordo com as pesquisas, atua diretamente sobre os processos emocionais, os mesmos que são exigidos durante um dilema pessoal moral. Por outro lado, esta mesma lesão não engendra alterações significativas na capacidade cognitiva que é necessária para fazer julgamentos impessoais morais. Isso quer dizer que a manutenção da normalidade em julgamentos impessoais de certo e errado - que mais supõe nossas funções cognitivas que nossas funções emocionais - , diz respeito ao fato de que, nesse caso específico, os raciocínios morais sofrem pouca influência das emoções. Como o córtex pré-frontal ventromedial guarda relações mais enfáticas com a formação e constituição dos processos emocionais, suas lesões não alteram os julgamentos de fundo cognitivo estrito. No caso dos dilemas pessoais morais, a anormalidade no padrão de julgamentos é um indicativo da influência que as emoções podem exercer, neste caso, sobre os raciocínios morais. Trata-se de um transtorno neuropsicológico capaz de modificar nossa própria estrutura cognitiva, nos casos em que a interação e integração emoçãocognição são imprescindíveis para o raciocínio moral em dilemas pessoais morais. Neste caso, a normalidade da estrutura cognitiva reclama uma equilibrada integração emoção-cognição. Se julgamentos de dilemas morais por parte de indivíduos não afetados são marcados por essa integração equilibrada é justamente porque a estrutura cognitiva não prescinde da influência das emoções ${ }^{6}$.

Uma das mais importantes inserções em pesquisas sobre a personalidade e as emoções é a de Richard Davidson, cujo projeto de uma "biologia da personalidade e das emoções" supõe os papéis preponderantes do córtex pré-frontal (doravante CPF) e da amígdala. Apoiado em estudos 
com a MRI, a fMRI e o PET, Davidson (2008, p. 192) fornece uma importante contribuição ética, mais especificamente sobre o processo de regulação de emoção no córtex pré-frontal:

\begin{abstract}
Em humanos e primatas não-humanos, é indubitável que o córtex exerce importante papel na emoção. Pesquisas com humanos têm lançado luz sobre o papel de vários territórios do córtex pré-frontal (CPF), e em especial os que são cruciais para diferentes aspectos da emoção. O CPF é especialmente importante para regulação de emoção e para as diferenças individuais. Regulação de emoção se refere ao processo que realça, suprime ou mantém uma resposta emocional, enquanto que o estilo afetivo se refere a diferenças individuais consistentes nos parâmetros básicos da reatividade emocional e da regulação de emoção. A descoberta dos mecanismos de reatividade emocional fornece um caminho mais direto para o entendimento de como os fatores genéticos e experimentais podem operar sinergeticamente em um percurso final comum para formar personalidade e emoção.
\end{abstract}

Com efeito, embora o CPF seja usualmente considerado a província das funções cognitivas superiores, uma de suas funções mais conhecidas é a participação na geração de vários processos afetivos. Estudos neurofisiológicos, neuropsicológicos e com neuroimagens em humanos e outros primatas parecem indicar que o CPF é requerido para produção de sinais que se dirigem a outras regiões cerebrais que guiam o comportamento. Do ponto de vista do comportamento ético, é particularmente significativo saber que recentes estudos eletrofisiológicos e com tecnologias de neuroimagem sugerem intrínsecas relações entre regiões do CPF e a representação de recompensas e punições (Davidson, 2003, p. 656; Whalen, 1998). O estudo do funcionamento individual da distribuição dos setores de recompensa e punição fornece um entendimento relevante para compreensão do comportamento de cada indivíduo em função da dialética recompensa-punição e, sobretudo, para a compreensão dos transtornos de humor (Herrington et all, 2006, p. 133)7.

Sobre o estudo acerca dos sistemas neurais de recompensa-punição, cuja implicação para as Éticas Contemporâneas pode ser importante, podemos dizer que grande parte do conhecimento adquirido acerca das associações entre memória e emoções resulta de estudos do condicionamento clássico do medo, na mesma medida em que o medo condicionado gera reações que envolvem as mesmas características que as situações efetivamente ameaçadoras: imobilização dos movimentos, elevação da pressão arterial e da frequência cardíaca, superficialidade da respiração, assim como facilidade e rapidez para o sobressalto. Do ponto de vista da constituição da memória emocional, como se sabe desde o surgimento dos laboratórios de Psicologia Experimental, cumpre ressaltar que, no medo condicionado, há uma associação entre um estímulo relativamente neutro (o estímulo condicionado, EC) e um evento aversivo, ao qual é pareado, em dado momento, por uma razão que pode ser objetiva ou meramente idissioncrática.

No condicionamento ao medo, os neurônios de algumas regiões cerebrais — que parecem ser os responsáveis pela associação de um evento a uma resposta condicionada - tendem a interpretar certos estímulos de maneira diferenciada. Há muito pouco tempo, foram descobertos os principais 
componentes destes circuitos da memória emocional. Antes, o estudo do condicionamento clássico do medo enfatizava mais diretamente o papel do córtex auditivo, e depois, o tálamo e o mesencéfalo, no tanto quanto se relacionam de maneira direta com algumas zonas subcorticais. Atualmente, porém, sabe-se que a memória emocional e, subsequentemente, os circuitos neurais do medo supõem alguns mecanismos neuro-hormonais, neurofisiológicos, neuroquímicos e neuroelétricos, assim como o papel preponderante dos núcleos central e lateral (mais especificamente, o dorsolateral) da amígdala, no tanto quanto participam dos processos emocionais de forma decisiva.

Os núcleos da amígdala participam dos comportamentos emocionais mediante atuação significativa no circuito de condicionamento do medo, e em função de sua conexão com inúmeras regiões do tronco cerebral que comandam específicas e relevantes reações comportamentais. $\mathrm{O}$ sistema do medo não é, como se supõe usualmente, um sistema que resulta da experiência do medo. Antes, trata-se de um circuito neuronal que "detecta o perigo e produz respostas que maximizam a probabilidade de sobrevivência a situações perigosas, pelo caminho mais benéfico" (LeDoux, 1996, p. 35). Trata-se, na verdade, da ideia de que nossa emoção mais primitiva é a que cria o comportamento defensivo: "para sobreviver, os animais e os homens precisam aprender desde cedo sobre as coisas e os lugares que potencialmente oferecem algum tipo de perigo" (LeDoux, 1995, p. 1029). Crendo que os comportamentos emocionais, como, por exemplo, os comportamentos defensivos, evoluíram de maneira independente, e antes dos sentimentos conscientes, LeDoux defende que representam a operação do sistema cerebral a qual independe da consciência, razão pela qual são designados de sentimentos inconscientes. LeDoux se inscreve na tradição contemporânea, junto com Paul Whalen, segundo a qual a compreensão de certas emoções, como o medo e a ansiedade, depende, em alto grau, da explanação das funções da amígdala, que é cada vez mais conhecida por sua independência em relação aos processos conscientes.

Nesse sentido, nada mais natural do que ser levado à seguinte indagação: tendo em vista a independência das emoções em relação aos processos conscientes, mesmo no âmbito de convincentes relações de interação e integração entre raciocínios morais e emoções, como pensar qualquer modelo ético na contemporaneidade? Nossos atos e escolhas são mais determinados por processos emocionais básicos do que por decisões conscientes? Enfim: o que resta de voluntário no homem?

\subsection{Dilemas Filosóficos?}

Diante desse quadro, um filósofo pode e deve se perguntar: O que resta de voluntário no homem? Quais setores do comportamento não estão descritos de maneira objetiva e causal no rol de ações explicadas pelo funcionamento arterial, químico ou elétrico do cérebro? Assumindo o papel da cultura e das emoções subjetivas no âmbito dessa dinâmica, juristas, filósofos, teólogos e cientistas se veem diante da seguinte questão: alguém que execute determinações extrínsecas a seu 
suposto poder da vontade livre é tão responsável por seus atos e pelas consequências deles quanto aquele que se autodetermina?

Benjamin Libet (1985), o proponente de um experimento sobre a temporalidade da "consciência consciente", defende que a noção de livre-arbítrio não é imune a severas controvérsias: no cérebro, as ações voluntárias são precedidas por transformações elétricas que ocorrem cerca de 550 milésimos de segundo antes do início da ação, sendo que a consciência da ação ocorre depois, entre 350 e 400 milésimos de segundo depois que no cérebro se deu a específica transformação elétrica que denota 'prontidão para cumprir a ação', ou seja, 200 milésimos de segundo antes da própria ação. Isso quer dizer que a decisão voluntária, segundo Libet, se dá sem a contribuição da consciência; ademais, Libet também quer dizer que, entre o início da ação e sua realização, pode passar muito tempo, qual seja: o da consciência consciente, que implica a ativação do córtex frontal. Sem levarmos em consideração os já conhecidos equívocos metodológicos que caracterizam o experimento de Libet em sua intenção última de salvaguardar o livre-arbítrio, o experimento muito contribuiu para reconfigurar as questões éticas em novo plano, desbastado-as de sua antiga vocação "metafísica". A sequência temporal que compreende o início e o controle das ações voluntárias é constituída pela conjunção e colaboração recíproca entre uma série de áreas motoras internas e externas ao córtex cerebral. Estas áreas, por sua vez, também dependem dos gânglios da base, que são estruturas subcorticais muito próximas do sistema límbico $^{8}$, a principal área envolvida na constituição e geração de emoções, onde não há controle da consciência consciente. Ou seja, o experimento de Libet tende a defender que a realização do ato voluntário depende do papel decisivo de áreas cerebrais que não são conscientemente controladas ${ }^{9}$.

Há estudos, porém, que apontam para a possibilidade de uma Neurociência da vontade e da ação voluntária, dentre os quais Patrick Haggard (2008, p. 936), para quem os cérebros dos humanos e dos primatas "contêm muitos circuitos corticais motores distintos que contribuem para a ação voluntária. Esses circuitos convergem para o córtex motor, que executa comandos motores pela transmissão deles à corda espinhal e músculos”. Opondo-se à visão filosófica segundo a qual o pensamento consciente causa a ação, Haggard tem sido muito importante na defesa do modelo neurocientífico de decisões. Defendendo que a cultura e a educação representam um poderoso aprendizado para os circuitos cerebrais cognitivo-motores, Haggard afirma uma abordagem da responsabilidade que depende não apenas dos processos neurais que estão por trás da volição, mas também dos sistemas cerebrais que nos capacitam para compreensão de como a sociedade constrange a volição, e de como nos adaptamos apropriadamente a essas obrigações. Obviamente, uma compreensão básica do funcionamento do cérebro social, assim como do cérebro cognitivomotor, é essencial para nosso conceito convencional de responsabilidade para a ação. Também é certo, porém, que a volição supõe redes cerebrais que estabelecem uma série de complexas e abertas decisões entre as ações e opções alternativas que caracterizam a tomada de decisão ${ }^{10}$. Ou seja, há indícios de que mesmo a volição não pode ser concebida no âmbito de um sistema absoluto de 
liberdade: torna-se difícil, pois, justificar a ideia de consciência como vontade e inteligência. Se de fato podemos estar diante de certas alternativas morais a cada vez que somos levados a tomar uma decisão, sem dúvida existe um relevante fator condicionador não apenas dos rumos que tomaremos, mas também das próprias escolhas que se nos aparecem como possíveis: os sistemas neurobiológicos que, atuando em função da diversidade de satisfações e desconfortos aos quais estamos submetidos, nos apresenta escolhas com consequências múltiplas.

Inserindo-se em tal discussão, Francisco Ayala (2009, p. 1) faz a seguinte ponderação: "a questão de se o comportamento ético é biologicamente determinado deve também se referir à capacidade para Ética”, isto é, à capacidade de julgar as ações humanas como certas ou erradas, e também à “aceitação das normas morais pelos seres humanos para guiar suas ações”. Se os homens são seres morais por natureza, afirma Ayala, isso se deve à pré-disposição que temos para julgar as ações humanas como certas ou erradas em termos de suas consequências para outros seres humanos: "nesse sentido, humanos são seres morais por natureza porque sua constituição biológica determina a presença neles de três condições necessárias para o comportamento ético", no caso: (i) habilidade para antecipar as consequências de nossas próprias ações; (ii) habilidade para fazer juízos de valor; (iii) habilidade para escolher entre alternativas no curso da ação. O comportamento ético, segundo a perspectiva evolucionista de Ayala, se estruturou em busca da possibilidade de fazer predições comuns e cotidianas em relação ao futuro, a mesma capacidade que levou nossos ancestrais a produzir ferramentas para a vida na Terra.

Respondendo à perspectiva de Ayala, Michael Ruse (2009) considera que a biologia deve ser considerada de maneira irrestrita o fundamento da ética. Ainda que ambos considerem a ética e a moralidade no âmbito de uma explicação naturalística, Ruse não faz restrições à biologia enquanto fundamento da ética. A ética é produto exclusivo da seleção natural. Trata-se de uma adaptação, a mesma que nos conferiu "mãos", "dentes" e o fato de andarmos sobre as pernas. Os homens, pois, fazem parte do mundo animal, e a moralidade é apenas um instrumento para a boa e segura vida na Terra, assim como os animais produzem suas próprias regras no espaço de convivência.

\section{Conclusões}

Neste artigo, meu objetivo geral consistiu em apresentar um modelo investigativo que ainda está em construção, razão pela qual não é imune a severas controvérsias e desconfianças. Esta característica não nos surpreende, sobretudo porque a associação com certos postulados e hipóteses neurocientíficas pode sugerir uma aproximação indevida com um modelo fisicalista e reducionista. Com efeito, uma orientação reducionista pode ser capaz de excluir por completo a hipótese de um diálogo entre Filosofia e Ciência. Este é o motivo pelo qual devo pontuar que minha estratégia defender a possibilidade de uma colaboração recíproca entre Filosofia e Ciência — visa a reconhecer 
a possibilidade de levarmos em consideração certas hipóteses neurocientíficas no âmbito de uma perspectiva crítico-filosófica. Para tanto, é importante sugerir que consideremos uma hipótese apenas como um mecanismo eficaz de trazer novos e reiterados desafios às discussões contemporâneas. No nosso caso, novos dados e novos desafios às contemporâneas discussões da Ética. Tal proposta só é possível em função da profunda dinamicidade que caracteriza o debate atual da Ética contemporânea, a mesma vantagem que engendra os inúmeros argumentos e contra-argumentos que têm alimentado a defesa e as críticas às mais diversas correntes atuais éticas.

Há algum tempo, a antiga ideia de que a Ciência se propõe dotada de verdade(s) absoluta(s) não faz parte dos discursos científicos. Trata-se de uma discussão metodológica bem presente desde os primeiros períodos dos cursos de graduação de formação científica. Por outro lado, são também problemáticas as definições usuais e clássicas do conceito de Ciência, razão pela qual preferi assumir a posição de simplesmente aceitar a Filosofia como um saber cuja particularidade não se confunde com os métodos experimentais que indicam o nível de cientificidade de um dado saber.

Por um lado, minha proposta teórico-metodológica não prescinde do reconhecimento de que os avanços conceituais e empíricos das Neurociências podem, em algum momento, e sob certas circunstâncias, reconfigurar o equacionamento de certos problemas éticos, especialmente no que diz respeito às bases psicofisiológicas dos processos de decision-making. Por outro lado, não posso deixar de reconhecer que a produção científica se tornou capaz de trazer efetivas contribuições a uma série de problemas filosóficos justamente porque soube assimilar o espírito da dúvida em relação a seus resultados e metodologia, o que pode inserir as Neurociências no mesmo contexto dinâmico e vivo que tem caracterizado as Éticas contemporâneas.

Com efeitos, muitos têm sido os esforços para delinear as bases neurais dos processos de tomada de decisão. Por isso mesmo, chegamos ao ponto de poder reproduzir em laboratório algumas condicionantes psicofisiológicas que tendem a estar na base de inúmeras tendências psicocomportamentais. Isso, porém, não justifica qualquer minimização das discussões teóricas acerca do livre-arbítrio e da capacidade de escolha, seja por estar no âmbito de outro framework, no qual não é necessário pensar em processos psicofisiológicos, seja pela capacidade que a Filosofia sempre apresentou para dialogar com os mais recentes conhecimentos científicos. Fica, assim, completamente salvaguardada a possibilidade de diálogo entre a proposta aqui apresentada e outras correntes da Ética contemporânea.

De fato, muitos são os filósofos e neurocientistas que têm se debruçado sobre o problema das tomadas de decisão. Certas questões, no entanto, ainda dependem de profundas e futuras investigações, como mostram Walter e Schleim (2008, p. 44): (i) Qual a contribuição de cada nó da "rede da moral" no cérebro? (ii) Qual o papel desempenhado por aspectos sociais e autorreferentes nas decisões de cunho moral? (iii) Quais princípios morais são inatos e quais podem ser aprendidos? (iv) Será que tomografias cerebrais e outros procedimentos por imagem podem ajudar a avaliar 
o potencial de risco de criminosos individualmente? Sem dúvida, já temos um primeiro grande passo para tentar encaminhar uma resolução para tais dificuldades: o reconhecimento das emoções como peças-chave para a compreensão da mente humana, como já mostrara William James (1894). Como advertem Walter e Schleim (2008, p. 45), "experimentos dos fisiologistas da moral têm se mostrado frutíferos. Eles apontam para processos que não seriam reconhecíveis apenas pela reflexão e observação". Por enquanto, concluem, "pode-se afirmar que a racionalidade abstrata parece desempenhar um papel claramente menos importante na Ética do dia-a-dia do que o de nossos sentimentos". 


\section{Notas}

${ }^{1}$ Cf. (Gray, Braver e Raichle, 2002).

${ }^{2}$ Howard Gardner, em The Mind's New Science (1987), reconheceu a irrelevância dos fatores emocionais ou afetivos como uma das cinco características que sustentam as ciências cognitivas. Ulric Neisser, em Cognitive Psychology (1967), também afirma o desprezo das ciências cognitivas aos fatores dinâmicos (como as emoções) que motivam o comportamento. Jerry Fodor (1975), em The Language of Thought, afirma, nesta que é uma das principais obras que deram origem à ciência cognitiva, que as emoções são estados mentais completamente extrínsecos à explicação cognitiva. Um pouco mais recentemente, Barbara Von Eckardt, em What is Cognitive Science (1995), sustenta que a maior parte dos cientistas cognitivos não considera o estudo das emoções relevante para esse ramo (LeDoux, 1996, p. 35).

${ }^{3}$ Tal condição só começou a se modificar em tempos de modernidade, e remete claramente ao progressivo e gradual avanço das ciências e recursos tecnológicos. Pelas mãos de pesquisadores como William James (1884), Walter Cannon e Philip Bard (1929), James Papez (1937) e Paul MacLean (1990), e a partir do apoio em dados clínicos e em pesquisas com animais, determinadas estruturas cerebrais começaram a ser caracterizadas como responsáveis pela geração e constituição das emoções. A conexão que estabeleceram entre as regiões do cérebro que modulam sistemas neurais capazes de gerar e controlar respostas emocionais é, sem dúvida, a origem mais precisa de uma neurociência dos afetos. Com efeito, os trabalhos de Freud muito contribuíram para desmitificar a clássica e equivocada dicotomia ontológica entre razão e emoções. Com William James, especialmente com seu texto What is an emotion? (1884), as emoções ficaram definitivamente consagradas como peças-chave para a compreensão da mente humana. Momento ainda mais marcante é o representado pela publicação de The expression of the emotions in man and animals (1872), de Charles Darwin. Com a publicação deste trabalho - inédito em função do apoio simultâneo em técnicas de observação e em princípios explicativos - Darwin fundamenta um novo e bem definido campo do saber, a etologia ou biologia do comportamento, isto é, o estudo dos comportamentos humano e animal. A grande contribuição de Darwin foi a de ter desvendado o paralelismo ou complementaridade entre a estrutura corporal e padrões de comportamento, situando estes últimos como fatores hereditários e de união dos membros particulares em espécies, gêneros e unidades taxonômicas maiores. Trata-se do primeiro grande trabalho de psicobiologia, cujo suporte na teoria da seleção natural exerceu profunda influência nas Neurociências dos séculos XX e XXI, que consagraram definitivamente as emoções como problema filosófico-científico. Darwin foi um dos primeiros a reconhecer de maneira realmente precisa os efeitos corporais das emoções, isto é, a relação entre certos estados da mente e certas ações complexas.

${ }^{4}$ Essa região inclui principalmente o córtex pré-frontal medial (CPFM), o sulco temporal superior (STS), os polos temporais anteriores e o córtex orbitofrontal (COF). Nessa "rede moral", são também supostas as regiões anteriores da ínsula (as regiões não granuladas), que mantêm conexões específicas e recíprocas com “as regiões 'límbicas', tais como o córtex cingular posterior (CCP), o córtex pré-frontal ventromedial (CPFVM), a amígdala e o estriado ventral”, razão pela qual se atribui à insula "um papel na integração das informações autonômicas e viscerais nas funções emocionais e motivacionais" (Naqvi e Bechara, 2008, p. 57). A arquitetura química da ínsula anterior tem características específicas para o desempenho de papel significativo na motivação e nas emoções, justamente por conter grande densidade de receptores de dopamina, um precursor natural da adrenalina e da noradrenalina, e cuja função é a de estimular os receptores adrenérgicos e dopaminérgicos do sistema nervoso simpático.

${ }^{5}$ Estudos de neuroimagem têm demonstrado que o desenvolvimento do córtex pré-frontal se relaciona de maneira íntima com o aprimoramento de distintas capacidades emocionais, dentre as quais: melhoras na modulação afetiva, na avaliação da recompensa e na discriminação precisa de situações com alto conteúdo emocional. Tal aprimoramento está relacionado com a mielinização, isto é, com a formação da bainha lipídica que recobre o axônio dos neurônios, de modo a isolá-los eletricamente e aperfeiçoar a transmissão do impulso nervoso. O aumento dos níveis da bainha de mielina é o que engendra a melhora no processamento cognitivo e a refinação do controle do comportamento impulsivo e da dinâmica comunicacional, o que ocorre por volta dos 12 aos 18 anos.

${ }^{6}$ Em outros textos, Antonio Damasio também esclarece que lesões no CPFVM exercem papel significativo nos processos de escolha: os afetados não apresentam capacidade de agregar sinais emocionais ao seu comportamento, apresentando também grandes dificuldades para tomar decisões em situações que dependem muito das emoções. Nestes indivíduos, decisões utilitaristas são tomadas com muito mais frequência, o que os levam a decidir comumente por situações aritmeticamente "mais favoráveis". Comentando os resultados desta pesquisa pioneira, Jorge Moll e Ricardo de Oliveira-Souza (2007b, p. 1) afirmam que "muitos estudos têm documentado mudanças no comportamento social a partir de danos em diferentes estruturas corticais e subcorticais". Tais comportamentos prejudiciais podem variar da "inadequação social (por exemplo, falta de tato social) a severas violações morais (por exemplo, a pedofilia)". Embora existam extensivas evidências que indiquem o papel de "muitas regiões do cérebro na implementação e regulação do comportamento moral, o córtex pré-frontal ventromedial (CPFVM) tem sido o mais focado nesse campo" (Ibidem). Segundo David Pizarro (2008, p. 50), os julgamentos desses indivíduos "parecem não se influenciar com a 
perspectiva de empurrar alguém à morte, desde que a matemática funcione”, isto é, desde que estejam 'conscientes' de que imediatamente podem salvar um número maior de pessoas. Trata-se de uma lesão que tem influência na redução dos chamados "sentimentos pró-sociais", que incluem culpa, compaixão, tolerância e empatia, o que decerto confere vantagens à estrutura do pensamento "impiedoso" e "racional".

7 Sabe-se que a depressão e a ansiedade estão associadas com padrões anormais de atividade cerebral assimétrica, particularmente nas regiões frontais. De fato, dados resultantes de pesquisas com neuroimagens indicam um papel importante das regiões frontais direita e esquerda em emoções positivas e negativas. Nos últimos anos, esclareceu-se que as função cerebrais assimétricas podem ser entendidas não apenas em termos de teorias da emoção, mas também em termos de construções específicas de personalidade.

${ }^{8}$ Segundo a fisióloga Silvia Nishida (2007, p. 166), "O sistema límbico forma um conjunto de estruturas corticais e subcorticais responsáveis pela interpretação e expressão das emoções, cujo circuito é conhecido como circuito de Papez. O hipotálamo faz parte do circuito recebendo informações do sistema límbico, especificamente do hipocampo. Dos corpos mamilares, o hipotálamo conecta-se com o tálamo. Outra área do sistema límbico chamado área septal também se conecta ao hipotálamo e, finalmente, recebe da amígdala o botão disparador das emoções. Esse conjunto de informações possibilita ao hipotálamo organizar as expressões viscerais e somáticas das emoções. Assim, quando ficamos ansiosos, o hipotálamo realiza uma serie de ajustes autonômicos".

${ }^{9}$ As duras críticas que se voltam para a metodologia do experimento da temporalidade da "consciência consciente" dizem respeito ao fato de manter que a consciência decide o resultado da ação por meio de facilitações ou inibições: a consciência decide se a ação terá lugar, ainda que não dê início à ação voluntária. Libet (1994; 2003, p. 26) propôs um campo da consciência mental testável, que emerge de funções cerebrais apropriadas. Trata-se da possibilidade de unificar a consciência experiente (que se baseia em um imenso número de diferentes eventos neurais), e sobretudo da crença de que a consciência experiente é capaz de afetar certas atividades neurais que fornecem uma gama de possibilidade para a ação da consciência livre no cérebro.

${ }^{10}$ A área motor pré-suplementar (preSMA) é, de acordo com Haggard, a peça-chave "desta rede de áreas que contribuem para as decisões" (2008, p. 944). Destarte, mais importante que o estudo da ação voluntária é o exame dos processos de decisão, o que supõe o CPFM. 


\section{Referências}

AYALA, Francisco. What the Biological Sciences Can and Cannot Contribute to Ethics. In: AYALA, Francisco; ARP, Robert. Contemporary Debates in Philosophy of Biology. Oxford: Wiley-Blackwell, 2009.

DARWIN, C. The Expression of Emotions in Man and Animals. 3. ed. New York: Oxford University Press, 1998.

DAVIDSON, Richard. Toward a Biology of Personality and Emotion. Annals New York academy of sciences, New York, v.1, n.1, 2008, p. 191-207.

Affective neuroscience and psychophysiology: toward a synthesis. Psychophysiology, Wisconsin, v. 40, 2003, p. 655-665.

GRAY, Jeremy; BRAVER, Todd; RAICHLE, Marcus. Integration of emotion and cognition in the lateral prefrontal cortex. PNAS, New York, v. 99, n. 6, march/2002, p. 4115-4120.

GREENE, Joshua; SOMMERVILLE, R. Brian; LEIGH, E. Nystrom; DARLEY, John M.; COHEN, Jonathan D. An fMRI Investigation of Emotional Engagement in Moral Judgment. Science, v. 293, September/2001, p. 2105-2108.

The Neural Bases of Cognitive Conflict and Control in Moral Judgment. Neuron, v. 44, $\overline{\text { October }} / 2004$, p. 389-400.

.; HAIDT, Jonathan. How (and where) does moral judgment work? Trends in Cognitive Sciences, v. 12, n. 9, December/2002, p. 517-523.

HAGGARD, Patrick. Human volition: towards a neuroscience of will. Nature reviews/ neuroscience, v. 9, December/2008, p. 934-946.

HERRINGTON, John; KOVEN, Nancy ; MILLER, Gregory; HELLER, Wendy. Mapping the Neural Correlates of Dimensions of Personality, Emotion, and Motivation. In: CANLI, Turran. Biology of personality and individual differences. New York: The Guilford Press, 2006, p. 133156.

HAUSER, Mark. Moral minds. How nature designed our universal sense of right and wrong. New York: Harper Collins, 2006.

ILLES, Judy; BIRD, Stephanie. Neuroethics: a modern context for ethics in neuroscience. Trends in neurosciences Elsevier, v. 30, n. 10, doi:10.1016, 2006, p. 1-7.

JAMES, William. What is an emotion?, Mind, v. 19, p. 188-205, 1884.

KOENIGS, Michael; YOUNG, Liane, DAMASIO, Antonio et all. Damage to the prefrontal cortex increases utilitarian moral judgments. Nature, v. 446, abril/2007, p. 908-911.

LEDOUX, Joseph. The Emotional Brain. New York: Simon \& Schuster, 1996.

Fear conditioning enhances short-latency auditory responses of lateral amygdala neurons: parallel recordings in the freely behaving rat. Neuron, New York, v. 15, 1995, p. 1029-1039.

MOLL, Jorge; OLIVEIRA-SOUZA, Ricardo. Primeiro sentimos, depois julgamos. Mente e cérebro, São Paulo, v. 1, n. 187, agosto/2008, p. 46-51.

MOLL, Jorge; OLIVEIRA-SOUZA, Ricardo. Moral judgments, emotions and the utilitarian brain. 
Trends Cognitive Science, v. 30, n. 10, june/2007b, p. 1-3.

MOLL, Jorge; OLIVEIRA-SOUZA, Ricardo; ESLINGER, Paul. Morals and the human brain: a working model. Neuroreport, v. 14, n. 3, march/2003, p. 299-305.

NAQVI, Nasir; BECHARA, Antoine. The hidden island of addiction: the insula. Trends in neurosciences Elselvier, California, v. 32, n. 1, 2008, p. 55-67.

NISHIDA, Silvia. Hipotálamo. Curso de Fisiologia 2007/ Ciclo de Neurofisiologia, Departamento de Fisiologia da UNESP, Botucatu-SP, 2007, p. 166-172.

PANKSEPP, Jaak. Affective Neuroscience: the foundations of human and animal emotions. New York: Oxford University Press, 1998.

PIZARRO, David. A virtude de ser do contra. Mente e cérebro, São Paulo, v. 1, n. 187, agosto/2008, p. 50 .

RUSE, Michael. The biological sciences can act as a ground for Ethics. In: AYALA, Francisco; ARP, Robert. Contemporary Debates in Philosophy of Biology. Oxford: Wiley-Blackwell, 2009.

WALTER, Henrik; SCHLEIM, Sthepan. Pelos trilhos da Ética. Mente e cérebro, São Paulo, v. 1, n. 187 , agosto/2008, p. 40-45.

WHALEN, John Paul. Fear, vigilance, and ambiguity: initial neuroimaging studies of the human amygdala. Current Directions in Psychological Science, Washington, v. 7, n. 6, 1998, p.177-188. 